\title{
The effects of farmers' adoption behavior of soil and water conservation measures on agricultural output
}

Xiaohui Huang

Business School, Jiangsu Normal University, Xuzhou, China, China

Qian Lu

College of Economics and Management, Northwest Agriculture and Forestry University, Yangling, China, and

\author{
Fei Yang
}

Business School, Jiangsu Normal University, Xuzhou, China
Effects of farmers' adoption behavior

Received 10 February 2020 Revised 28 May 2020 15 July 2020 Accepted 21 July 2020

\begin{abstract}
Purpose - This paper aims to build a theoretical model of the impact of farmers' adoption behavior of soil and water conservation measures on the agricultural output to analyze the impact of farmers' adoption behavior of soil and water conservation measures on agricultural output.

Design/methodology/approach - Based on the field survey data of 808 farmers households in three provinces (regions) of the Loess Plateau, this paper using the endogenous switching regression model to analyze the effect of farmers' adoption behavior of soil and water conservation measures on agricultural output.

Findings - Soil erosion has a significant negative impact on agricultural output, and soil erosion has a significant positive impact on farmers' adoption of soil and water conservation measures. Farmers adopt soil and water conservation measures such as engineering measures, biological measures and tillage measures to cope with soil erosion, which can increase agricultural output. Based on the counterfactual hypothesis, if farmers who adopt soil and water conservation measures do not adopt the corresponding soil and water conservation measures, their average output per ha output will decrease by $2.01 \%$. Then, if farmers who do not adopt soil and water conservation measures adopt the corresponding soil and water conservation measures, their average output per ha output will increase by $12.12 \%$. Government support and cultivated land area have a significant positive impact on farmers' adoption behavior of soil and water conservation measures.
\end{abstract}

Research limitations/implications - The research limitation is the lack of panel data.

Practical implications - Soil erosion has a significant negative impact on agricultural output, and soil erosion has a significant positive impact on farmers' adoption of soil and water conservation measures. Farmers adopt soil and water conservation measures such as engineering measures, biological measures and tillage measures to cope with soil erosion, which can increase agricultural output.

(C) Xiaohui Huang, Qian Lu and Fei Yang. Published by Emerald Publishing Limited. This article is published under the Creative Commons Attribution (CC BY 4.0) licence. Anyone may reproduce, distribute, translate and create derivative works of this article (for both commercial \& noncommercial purposes), subject to full attribution to the original publication and authors. The full terms of this licence may be seen at http://creativecommons.org/licences/by/4.0/legalcode

Foundation projects: This paper is supported by the National Natural Science Foundation of China (Project Nos. 71673223 and 71973105). Xuzhou social science research project(20XSM-116); Jiangsu Normal University Youbo research start-up fund project.

This paper forms part of special section "Climate change impacts and adaptations in arid and semi-arid regions", guest edited by Zhihua Zhang, Qiang Zhang and Muhammad Jawed Iqbal.

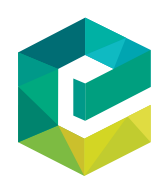

International Journal of Climate Change Strategies and Management Vol. 12 No. 5, 2020 pp. 599-615
Emerald Publishing Limited Emerald Publishing Limited
$1756-8692$ DOI 10.1108/IJCCSM-02-2020-0014 
IJCCSM 12,5

Social implications - The conclusion provides a reliable empirical basis for the government to formulate and implement relevant policies.

Originality/value - The contributions of this paper are as follows: the adoption behavior of soil and water conservation measures and agricultural output are included into the same analytical framework for empirical analysis, revealing the influencing factors of farmers' adoption behavior of soil and water conservation measures and their output effects, enriching existing research. Using endogenous switching regression model and introducing instrumental variables to overcome the endogenous problem between the adoption behavior of soil and water conservation measures and agricultural output, and to analyze the influencing factors of farmers' adoption behavior of soil and water conservation measures and its impact on agricultural output. Using the counter-factual idea to ensure that the two matched individuals have the same or similar attributes, to evaluate the average treatment effect of the behavior of soil and water conservation measures, to estimate the real impact of adaptation measures on agricultural output as accurately as possible and to avoid misleading policy recommendations.

Keywords Agricultural output, Loess Plateau, Soil and water conservation measures, Soil erosion

Paper type Research paper

\section{Introduction}

Soil erosion has become a public hazard in the world, it is a serious threat to the human living environment. China is one of the countries with the most serious soil erosion in the world. The average loss of cultivated land due to soil erosion is about $66,666.67$ ha per year. The total amount of soil erosion reaches 5 billion tons every year, resulting in economic losses equivalent to 3.5\% of GDP (Xinhua News Agency, 2010). The total area of the Loess Plateau is $640,000 \mathrm{~km}^{2}$, of which the area of soil erosion reaches $454,000 \mathrm{~km}^{2}$. The sediment generated by soil erosion is about 1.6 billion tons per year, making it the most serious area of soil erosion in China (Wang, 2013). Therefore, choosing the Loess Plateau as the research area has certain representativeness. Soil and water loss has a far-reaching impact on China. Therefore, effective adaptation measures should be found to control soil and water loss and mitigate its adverse effects. The Chinese government attaches great importance to the control of soil erosion. In recent years, the Central Document No.1 has proposed to strengthen the control of soil erosion. In the field of agriculture, there is a significant coupling relationship between soil erosion and agricultural production. Agriculture is most sensitive to the changes in soil erosion. It not only causes a sharp decrease in the number of cultivated land but also causes land degradation and reduces the economic and ecological productivity of land (Ji, 2017). Farmers are the main undertakers and the most direct perceivers of ecological deterioration consequences such as soil erosion (Guo et al., 2017). Therefore, soil erosion has the most significant impact on farmers based on natural resources (Zhao, 2014). Specifically, soil erosion brings more uncertainty to farmers in the process of agricultural production, and farmers face more external production risks (Chen and Xie, 2013). Correspondingly, farmers are the main body of soil erosion control and rural ecological construction (Li, 2017). Risk-averse farmers will adopt a series of soil and water conservation measures to reduce the adverse impact of soil erosion on agricultural output, so as to reduce the potential production loss and risk of soil erosion (Di Falco and Chavas, 2009).

Soil and water conservation measures are important adaptation measures for farmers to cope with and resist the potential risk of soil erosion. For example, farmers can cope with and reduce the production risk caused by soil erosion through the construction of engineering measures such as soil and water conservation projects, biological measures such as grain for green and grass and conservation tillage measures such as less tillage and no-tillage (Ying, 2018).To a certain extent, the control of soil erosion depends on farmers' 
adoption behavior of soil and water conservation measures. Therefore, in recent years, the research on farmers' adoption behavior of soil and water conservation measures has become one of the hot topics in academic circles. A large number of studies have shown that individual characteristics (gender, age, education level, etc.), family management characteristics (income level, the scale of an agricultural operation, part-time behavior, number of the labor force), level of regional economic development, policy factors (agricultural technology training, extension system, government support, etc.) affect farmers' adoption behavior of soil and water conservation measures (Khisa et al., 2007; Jara-Rojas et al., 2012; Zhai and Hang, 2005). These studies have laid a theoretical foundation for this paper. However, scholars focus on the influencing factors of farmers' adoption of soil and water conservation measures, and there are few studies on the impact of soil and water conservation measures on agricultural output (Yang et al., 2016; Cai and Cai, 2012). Farmers as a "rational economic man," the most important basis for farmers to adopt soil and water conservation measures is their cost-benefit situation. If the adoption of soil and water conservation measures can improve farmers' profits or production efficiency, then the measures will be quickly spread and adopted by many farmers. In a certain period of time, if the adoption of soil and water conservation measures can not bring economic benefits such as cost-saving and yield-increasing to farmers, it will greatly affect the promotion of the measures. Therefore, the output effect is particularly important when farmers adopt soil and water conservation measures to deal with soil erosion. In addition, as a loess plateau area with serious soil erosion, there are fewer kinds of literature to quantitatively study farmers' adoption of soil and water conservation measures based on the large-scale field survey data and even fewer kinds of literature to put the influencing factors and effectiveness evaluation of farmers' adoption of soil and water conservation measures in the same analysis framework (Feng et al., 2017; Yang et al., 2018; Yang et al., 2016). So in the case of serious soil erosion in the Loess Plateau, do farmers adopt soil and water conservation measures to cope with soil erosion? In the process of adopting soil and water conservation measures, what are their effects and whether they can increase farmers' agricultural output? The answers to the above questions can encourage farmers to adopt soil and water conservation measures to cope with soil erosion, alleviate the adverse effects on agricultural production, stabilize agricultural production of farmers and ensure the sustainable development of the agricultural industry.

In view of this, this paper investigates the relationship between farmers' adoption of soil and water conservation measures and agricultural output in the Loess Plateau area where soil erosion is serious. To solve the above problems. The endogenous transformation model was used to analyze the impact of farmers' adoption of soil and water conservation measures on agricultural output, and to evaluate the average treatment effect of the adoption of soil and water conservation measures. The contributions of this paper are as follows:

- The adoption behavior of soil and water conservation measures and agricultural output is included in the same analytical framework for empirical analysis, revealing the influencing factors of farmers' adoption behavior of soil and water conservation measures and their output effects, enriching existing research.

- Using endogenous transformation model and introducing instrumental variables to overcome the endogenous problem between the adoption behavior of soil and water conservation measures and agricultural output, and to analyze the influencing factors of farmers' adoption behavior of soil and water conservation measures and its impact on agricultural output.
Effects of farmers' adoption behavior 
IJCCSM

12,5

602

- Using the counter-factual idea to ensure that the two matched individuals have the same or similar attributes, to evaluate the average treatment effect of the behavior of soil and water conservation measures, to estimate the real impact of adaptation measures on agricultural output as accurately as possible and to avoid misleading policy recommendations.

Based on the research objectives, the structure of this paper is as follows: the first part is the introduction; the second part is the theoretical analysis; the third part is the data source, model construction and variable definition; the fourth part is the analysis of the empirical results; the fifth part is the conclusion and based on the above analysis results, put forward policy recommendations.

\section{Theoretical analysis}

Influencing factors of farmers' adaptation to climate change. Temperature and precipitation are important climatic factors that affect farmers' adaptive decision of climate change, farmers are willing to take more adaptive measures when the temperature rises and precipitation decreases (Deressa et al., 2009). Truelove et al. (2015) found that farmers' perception of drought risk, awareness of the effectiveness of adaptation measures and social factors are the key factors affecting their climate change adaptation decision. Arslan et al. (2014) concluded that there is a positive relationship between climate change and conservation agriculture. Asfaw et al. (2016) concluded that when the difference between the maximum temperature and precipitation fluctuation in the growing season of crops increases, farmers will take measures to reduce the risk. Farmers will take various measures to adapt to extreme weather events (Chen and Xie,, 2013; Habiba et al, 2012; Huang et al., 2015).

With regard to the output effect of agricultural technology, academic circles have studied different agricultural technologies in different ways. Cai and Cai (2012) used data collected from field surveys across four counties of Anhui province, OLS regression methods to analyze the impact of conservation tillage techniques on rice yield. Results showed that compared to farmers who adopted traditional farming techniques, farmers who adopted conservation tillage technology had higher rice yields of $93 \mathrm{~kg} /$ hectares. Feng et al. (2017) showed that farmers' climate change adaptation decision-making can increase agricultural output. Based on survey data collected from 660 apple farmers in 8 apple base counties in Shaanxi. Under counterfactual assumptions, the study finds that if farmers who adapt to climate change did not take adequate measures, their agricultural yield would reduce by $3.72 \%$. Then, if farmers decide to take measures for adaptation, their agricultural yield would increase by $5.54 \%$. Luo et al. (2013) based on the data collected from 221 riceproducing households located in the upper reaches of the Taihu Basin, evaluated their economic effects by estimating input demand and output supply functions. Research results indicate that keeping other variables constant, the yield of rice increased by $0.04 \%(\mathrm{~kg} /$ hectares) when the adoption rate of soil testing and formula fertilization technology increased by $1 \%$. Yang et al. (2016) used a large-scale survey of 1,663 wheat plots of 889 households in five provinces in the NCP, built two-stage econometric models to quantitatively analyze the determinants of irrigation adaptation measures and assess the impacts of adaptation measures on wheat yield. They found that losses will reduce by $14.2 \%$ with an increase of $50 \%$ irrigation time (amounting to 0.9 irrigation times). Li et al. (2017) showed that conservation tillage technology had a significant positive impact on crop yield. Falco, et al. (2011) and Yesuf et al. (2008) took Ethiopian farmers as research objects and analyzed the impact of farmers' climate change adaptation decision-making on agricultural output. The results show that climate change adaptation decision-making can 
increase farmers' agricultural output. Zhao and Cai (2013) showed that chemical control integrated pest management technology (IPM) and biological control IPM technology had a significant positive impact on rice yield. Finger et al. (2011) and Mainuddin et al. (2011) agreed to improve irrigation conditions will reduce the fluctuation of food production caused by climate change and increase grain production. Therefore, the impact of farmers' adoption behavior of soil and water conservation measures on agricultural output needs to be further evaluated and verified (Maddison, 2006).

As a rational economic man, farmers usually adopt engineering measures such as soil and water conservation projects, biological measures such as grain for green and grass and conservation tillage such as less tillage and no-tillage to reduce the potential impact of soil erosion. These adaptation measures mainly affect agricultural output through water conservation, soil conservation and fertilizer conservation (Figure 1). For example, in China, biological measures, such as grain for green and grass, can enhance the water storage and retention capacity of the soil, regulate runoff, reduce flood peaks, conserve water sources, conserve water and soil, fix and improve soil and improve soil erosion resistance. Conservation tillage techniques, such as less tillage and no-tillage, are mainly used in agricultural land. By adopting certain methods, soil resistance conditions can be further improved, the water absorption capacity of the soil can be increased and the water storage capacity of the soil can be promoted (Ying, 2018). It can protect the original soil layer structure, improve soil permeability, increase soil humus and organic matter, enhance soil fertility, prevent nutrient loss in soil, improve fertilizer utilization efficiency and then affect agricultural output (Feng et al., 2017). The form of build a terrace around the water source can transform the "running paddy field, running fertilizer field and running soil field" into "protecting paddy field, protecting fertilizer field and protecting soil field."

In summary, farmers' adoption of soil and water conservation measures has a positive impact on agricultural output, but the impact needs to be further assessed. Based on the survey data of peasant households in areas with serious soil erosion, this paper uses the endogenous transformation model to analyze the impact of farmers' adoption of soil and water conservation measures on agricultural output.

\section{Data sources, variable selection and model setting}

\subsection{Data sources}

The data of this study came from the field survey of farmers in Shaanxi, Gansu and Ningxia provinces (districts) in the Loess Plateau from October to November 2016. Using a stratified random sampling method to select survey sites and farmers. Each province chooses 2-3 counties (districts), namely, Mizhi County, Yuyang District, Suide County, Xifeng District, Huan County, Yuanzhou District, Pengyang County, Xiji County. Each County (districts) chooses 1-5 townships (towns). Each town randomly chooses 2-5 villages. Each village randomly extracts 15-20 farmers, total 1,200 questionnaires are collected. The survey

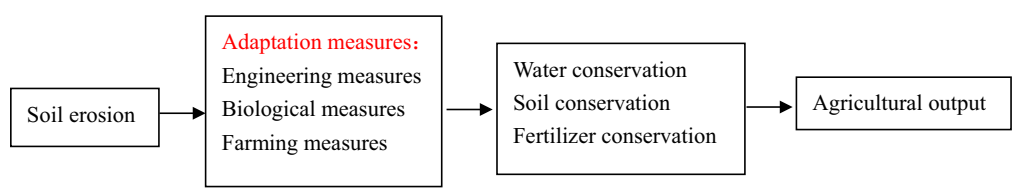

wer conservation measures on agricultural output.
Effects of farmers' adoption behavior

603 
IJCCSM 12,5

604 contents cover the capital endowment of farmers and families, the occurrence of soil erosion, farmers' adoption of soil and water conservation measures and the input-output situation of agriculture. Questionnaires were obtained through face-to-face interviews with farmers. To evaluate the agricultural output of soil and water conservation measures, the same crops are needed. Among the sample farmers, the corn growers are the most. Therefore, 808 maize growers should be taken as an example to analyze the output effect of farmers' adoption of soil and water conservation measures. Among the sample farmers, the proportion of men is larger, accounting for $97.28 \%$ of the total sample. Most of them are between 41 and 60 years old, accounting for $75.37 \%$ of the sample peasant households. This shows that with the advancement of urbanization, most of the young and strong labor force choose to go out to work. At present, the age of rural peasant households is older, which is in line with the actual situation of the current rural areas. The education level of sample farmers is generally low, and the education level in junior middle school and below accounts for $90.47 \%$ of the sample. In total, $6.56 \%$ of peasant households joined cooperatives, with a low proportion. The basic situation of sample farmers is shown in Table 1.

\subsection{Variable selection and description}

Dependent variable. The adoption behavior of soil and water conservation measures. Soil and water conservation measures are technical packages including engineering measures, biological measures and tillage measures. They are effective measures for farmers to cope with soil erosion. Farmers often choose one or several combinations of measures in production practice, and the adoption of these measures is considered as farmers' adoption behavior of soil and water conservation measures. Agricultural output. On the basis of relevant research results, the yield per unit area of maize was used as the index of agricultural output in this paper.

Independent variable. Based on the relevant research results, this paper selected the severity of soil erosion, factor input, characteristics of peasant household and family endowment and instrumental variables as independent variables. This paper measures the severity of soil erosion by inquiring farmers' perception of the severity of soil erosion. Likert five-level scale was used to evaluate it. According to previous studies, this paper selected age, gender, education level, cultivated land area, whether to join cooperatives to represent farmers' capital endowment. The instrumental variables are government subsidies and mutual trust. Factor input chooses variables such as per ha fertilizer input, per ha pesticide input and per ha mechanical rental input. The definition and assignment of variables and descriptive statistical analysis are shown in Table 2.

\subsection{Model selection}

Because it is impossible to simultaneously observe the agricultural output of the same farmer under the two conditions of adopting and not adopting soil and water conservation measures, it is impossible to directly evaluate the impact of adopting soil and water conservation measures on the agricultural output of the farmer households. Therefore, this paper must consider the identification of causal effects when determining econometric models. At the same time, this paper uses the survey data of farmers. Whether farmers adopt soil and water conservation measures is not a random distribution, but optimal decision-making is made under various conditions or constraints (Cai et al., 2019). Farmers' adoption behavior of soil and water conservation measures has strong endogeneity. If the assessment of the effectiveness of adaptation measures does not consider the existence of endogenous problems, the estimated results of the model will have some deviation, which will mislead the proposed policy. Therefore, how to estimate the treatment effect of soil and water conservation measures on agricultural output under the consideration of the probability of 


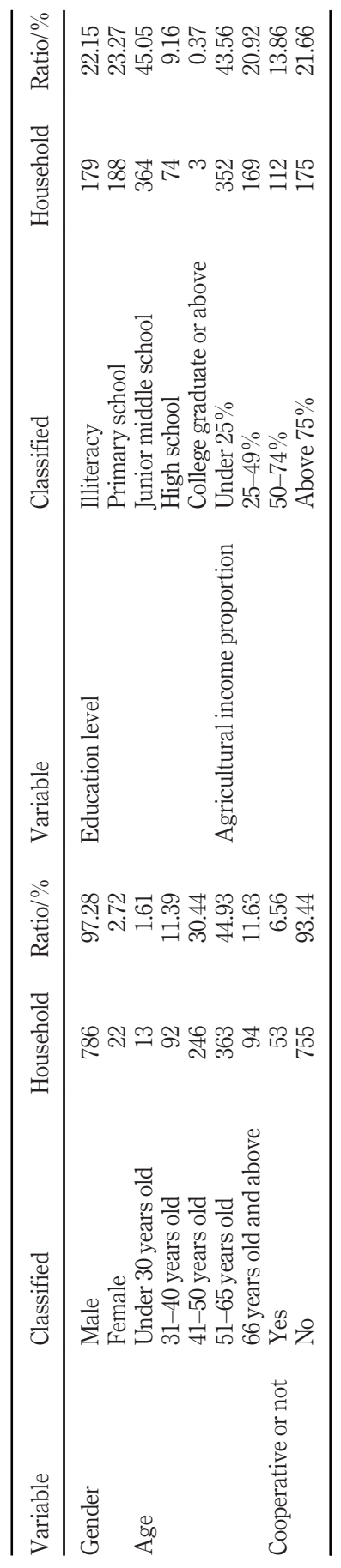

Effects of farmers' adoption behavior

605

Table 1. Basic situation of sample farmers 


\section{IJCCSM \\ 12,5}

\begin{tabular}{l} 
Variable \\
\hline Dependent variable \\
Agricultural output \\
Adaptation measures
\end{tabular}

606

Factor input
Fertilizer

Pesticide

Machinery

Instrumental variables

Government subsidies

Mutual trust

Endowment characteristics

Age

Education

Gender

Cultivated land area

Cooperatives
Table 2.

Explanations of variable and descriptive statistics
External environment

Seriousness of soil and water loss $1=$ no soil erosion, 2 = less serious, $3=$ general, $4=$ more serious and $5=$ very serious
Expected output per ha of maize (500 g)

Whether a farmer has adopted or not?

Yes $=1$ and no $=0$

Fertilizer input per ha (USD/ha)

Pesticide input per ha (USD/ha)

Machinery rental input per ha (USD/ha)

whether farmers get subsidies? Yes $=1$ and

no $=0$

The degree of mutual trust between people: no $=1$, few $=2$, general $=3$, more $=4$ and many $=5$

Below $20=1,21-30=2,31-40=3$,

$41-50=4,51-65=5$ and 66 above $=6$

Illiteracy $=1$, primary school $=2$, junior middle school $=3$, high school $=4$ and college graduate or above $=5$

$1=$ male and $0=$ female

Your cultivated and land area (ha)

Whether farmers join cooperatives? Yes $=1$ and no $=0$
$14,954.8358 \quad 8,661.9015$

$0.7116 \quad 0.4533$

$345.3040 \quad 306.7831$

$46.7891 \quad 114.6373$

$91.4791 \quad 155.1352$

$0.5735 \quad 0.3539$

$3.7252 \quad 0.9975$

4.5371

0.8967

2.4233

0.9454

0.9728

0.8128

0.1628

0.0656

0.7581

0.2477

3.7026

farmers adopting soil and water conservation measures, has become the key problem to be solved in this paper. To overcome the endogenous problem and avoid errors of the coefficients of evaluation, this paper used the endogenous switching regression model to solve the problem of sample selection bias caused by the heterogeneity of observable and non-observable factors.

First, constructing farmers' adoption behavior model of soil and water conservation measures. According to the expected utility theory, farmers adopt soil and water conservation measures in the context of soil erosion to maximize utility. $A_{i a}^{*}$ is the potential net benefit of farmers' adoption of soil and water conservation measures, $A_{i n}^{*}$ is the potential net benefit of farmers' non-adoption of soil and water conservation measures, $A_{i}^{*}=A_{i a}^{*}-A_{i n}^{*}$ is the expected utility difference between the two. If $A_{i a}^{*}>A_{i m}^{*}$, i.e. $A_{i}^{*}>0$, then farmers will adopt soil and water conservation measures, on the contrary, farmers will not adopt them. $A_{i}^{*}$ can not be observed directly, but can be expressed as a linear function of observable exogenous variables. The model of farmers' adoption behavior of soil and water conservation measures is as follows:

$$
A_{i}^{*}=C_{i} \eta+\nu_{i} \text { when } A_{i}= \begin{cases}1 & A_{i}^{*}>0 \\ 0 & A_{i}^{*} \leq 0\end{cases}
$$

In formula equation (1), $A_{i}^{*}$ represents the unobservable potential variable of farmers' adoption of soil and water conservation measures, $A_{i}$ represents farmers' adoption behavior 
of soil and water conservation measures and $C_{i}$ represents the vector of exogenous factors affecting farmers' adoption behavior of soil and water conservation measures. $\eta$ denotes the coefficients to be estimated; $v_{i}$ denotes a random error term:

$$
A_{i}=\alpha_{0}+\alpha_{1} X_{i}+\alpha_{2} B_{i}+\alpha_{3} I V_{i}+\varepsilon_{i}
$$

In equation (2), $A_{i}$ is the dependent variable, indicating whether farmers adopt soil and water conservation measures or not, If it is equal to 1 , it means to adopt; if it is equal to 0 , it means not to adopt and Bi represents the severity of soil and water loss, that is, the main purpose is to analyze the impact of the severity of soil and water loss on farmers' adoption of soil and water conservation measures. To ensure the identifiability of the endogenous transformation model, government subsidies and social trust are used as instrumental variables in farmers' behavior decision-making models of soil and water conservation measures. The reasons for choosing government subsidies as an instrumental variable are as follows: first, the implementation of government subsidies policy is the behavior of the main body above the village level, which only affects the farmers' adoption of soil and water conservation measures, but does not affect the final output of farmers; Second, in recent years, the government has continuously increased subsidies for soil erosion control. It is of great significance to evaluate the role of government subsidies in promoting farmers' adoption of soil and water conservation measures and to resist the negative impact of soil erosion. The reason for choosing social trust as an instrumental variable is that social trust only affects farmers' adoption of soil and water conservation measures, but does not affect farmers' final output. $X_{i}$ is the capital endowment of peasant households, which includes age, education level, gender, whether to join cooperatives, cultivated land area. Cluster $\alpha$ denotes the vector of coefficients to be estimated and $\varepsilon_{i}$ denotes the random error term.

Equation (1) shows that the adoption behavior of soil and water conservation measures $\left(A_{i}\right)$ is an endogenous variable. If the least-squares method is chosen to estimate the impact of farmers' adoption of soil and water conservation measures on agricultural output, the results are biased. In addition, there may be unobservable factors that simultaneously affect the random error terms $v_{i} \varepsilon_{i}$ of equations (1) and (2). It leads to the correlation between error terms $v_{i}, \varepsilon_{i}$. If selectivity bias is neglected, the estimation results will be inconsistent. Propensity score matching (PSM) can solve this problem, however, it can only solve the heterogeneity of observable factors (Maddison, 2006), but can not solve the heterogeneity of unobservable factors. Therefore, the endogenous switching regression model (ESRM) is chosen to solve the sample selectivity bias caused by the heterogeneity of observable and unobservable factors (Falco, 2011).

Second, establishing an evaluation model of the effect of soil and water conservation measures on agricultural output. The specific econometric models are as follows:

$$
\begin{gathered}
Y_{i a}=\chi_{0 a}+\chi_{1 a} X_{i a}+\chi_{2 a} B_{i a}+\chi_{3 a} D_{i a}+\chi_{4 a} A_{i a}+\theta_{i a} \\
Y_{i n}=\chi_{0 n}+\chi_{1 n} X_{i n}+\chi_{2 n} B_{i n}+\chi_{3 n} D_{i n}+\chi_{4 n} A_{i n}+\theta_{i n}
\end{gathered}
$$

The dependent variables $Y_{\text {in }}$ in equations (3-a) and (3-b) denote the agricultural output (logarithmic in the operational model) of farmers who do not adopt soil and water conservation measures. $Y_{i a}$ indicates the agricultural output of farmers who adopt soil and water conservation measures (logarithmic in the operational model). To explore the effects of soil erosion severity and soil and water conservation measures on agricultural output. In addition, $D_{i}$ represents a set of traditional input variables (logarithm in operation model), namely, fertilizer input (USD/ha), pesticide input (USD/ha), machinery input (USD/ha) and
Effects of farmers' adoption behavior 
IJCCSM

12,5

608

other inputs (USD/ha). The other variables are the same as those in the first stage. $\chi$-cluster is the parameter to be estimated and $\theta$ is the error term.

Finally, evaluating the treatment effect of farmers' adoption of soil and water conservation measures. The endogenous switching regression model can estimate the average treatment effect of farmers' adoption of soil and water conservation measures by comparing the expected agricultural output of farmers and non-farmers in real and counterfactual scenarios.

Output expectations of farmers who adopt adaptation measures (treatment group):

$$
E\left[Y_{i a} \mid A_{i}=1\right]=X_{i a} \chi_{1 a}+B_{i a} \chi_{2 a}+D_{i a} \chi_{3 a}+\sigma_{u a} \lambda_{i a}
$$

Output expectations of farmers who not adopt adaptation measures (control group):

$$
E\left[Y_{i n} \mid A_{i}=0\right]=X_{i n} \chi_{1 n}+B_{i n} \chi_{2 n}+D_{i n} \chi_{3 n}+\sigma_{u n} \lambda_{i n}
$$

At the same time, two counterfactual hypotheses are considered, that is, the output expectations of farmers adopting adaptation measures in the case of not adopting adaptation measures:

$$
E\left[Y_{i n} \mid A_{i}=1\right]=X_{i a} \chi_{1 n}+B_{i a} \chi_{2 n}+D_{i a} \chi_{3 n}+\sigma_{u n} \lambda_{i a}
$$

The expected output value of farmers who have not adopted adaptation measures in the case of adopting adaptation measures:

$$
E\left[Y_{i a} \mid A_{i}=0\right]=X_{i n} \chi_{1 a}+B_{i n} \chi_{2 a}+D_{i a} \chi_{3 n}+\sigma_{u a} \lambda_{i n}
$$

Through equations (4) and (6), it is found that the treatment effect of the output of the farmers adopting adaptation measures as follows:

$$
\begin{aligned}
A T T_{i} & =E\left[Y_{i a} \mid A_{i}=1\right]-E\left[Y_{i n} \mid A_{i}=1\right] \\
& =X_{i a}\left(\chi_{1 a}-\chi_{1 n}\right)+B_{i a}\left(\chi_{2 a}-\chi_{2 n}\right)+D_{i a}\left(\chi_{3 a}-\chi_{3 n}\right)+\left(\sigma_{u a}-\sigma_{u n}\right) \lambda_{i a}
\end{aligned}
$$

Through equations (5) and (7), it is found that the treatment effect of the output of the farmers not adopting adaptation measures as follows:

$$
\begin{aligned}
A T U_{i} & =E\left[Y_{i a} \mid A_{i}=0\right]-E\left[Y_{i n} \mid A_{i}=0\right] \\
& =X_{i n}\left(\chi_{1 a}-\chi_{1 n}\right)+B_{i n}\left(\chi_{2 a}-\chi_{2 n}\right)+D_{i n}\left(\chi_{3 a}-\chi_{3 n}\right)+\left(\sigma_{u a}-\sigma_{u n}\right) \lambda_{i n}
\end{aligned}
$$

\section{Empirical results and analysis}

This paper used Stata 14.0 software and full information maximum likelihood method (FIML) to estimates the impact of farmers' adoption behavior of soil and water conservation measures on agricultural output. The results of the joint estimation of farmers' adoption behavior of soil and water conservation measures and agricultural output models are shown in Table 3 . The second column in Table 3 is the estimation results of the factors affecting farmers' adoption of soil and water conservation measures. The third column is the estimated results of the factors affecting the agricultural output of farmers adopting adaptation measures. The fourth column is the estimated results of factors affecting the agricultural output of farmers who have not 
adopted adaptation measures. The regression results in Table 3 show that the correlation coefficient $\sigma_{u a}$ between the error items of the model of adaptation measures adopted by farmers and the error items of the model of agricultural output adaptive measures adopted by farmers, and the correlation coefficient $\sigma_{u n}$ between the error items of the model of adaptation measures adopted by farmers and the error items of the model of the agricultural output of farmers not adopt adaptive measures. The estimated values of $\sigma_{u a} \sigma_{u n}$ are significant at a $1 \%$ level, which indicates that there is sample selectivity bias in the agricultural output model. Among them, the value of $\sigma_{u a}$ is positive, which indicates that the output of the adopted farmers is higher than that of the general farmers in the sample, while the value of $\sigma_{u n}$ is negative, which indicates that the output of the non-adopted farmers is lower than that of the general farmers in the sample (Akpalu and Normanyo, 2014; Huang and Wang, 2014).

\subsection{Regression analysis of the equation of farmers adopted soil and water conservation measures}

Age has a significant negative impact on farmers' adoption of soil and water conservation measures, at the $1 \%$ statistical level. This indicates that the younger the farmers are, the more likely they are to adopt soil and water conservation measures because many soil and water conservation measures need a certain amount of labor input and young farmers are more competent. The old farmers are conservative and have poor physical strength. With the increase of the age of householders, their acceptance of new knowledge and information is slower and they are easier to be influenced by traditional habits and are often more resistant to new technologies (Kabil and Rainis, 2015), so they are unwilling to adopt soil and water conservation measures to

\begin{tabular}{|c|c|c|c|}
\hline Variable & $\begin{array}{c}\text { Adoption } \\
\text { behavior model }\end{array}$ & $\begin{array}{l}\text { Agricultur } \\
\text { Adopting adaptation } \\
\text { measures }\end{array}$ & $\begin{array}{l}\text { Not adopting adaptation } \\
\text { measures }\end{array}$ \\
\hline Factor input & - & $0.0769 * * *(0.0247)$ & $0.1252^{* * * *}(0.0371)$ \\
\hline $\begin{array}{l}\text { Instrumental variables } \\
\text { Government subsidies } \\
\text { Mutual trust }\end{array}$ & $\begin{array}{r}0.0833^{* * * *}(0.0309) \\
0.0082(0.0437)\end{array}$ & - & - \\
\hline $\begin{array}{l}\text { Endowment characteristics } \\
\text { Age } \\
\text { Education } \\
\text { Gender } \\
\text { Cultivated land area } \\
\text { Cooperatives }\end{array}$ & $\begin{array}{r}-0.2602 * * *(0.0593) \\
-0.0348(0.0539) \\
0.1372(0.2947) \\
0.0677 * * *(0.0096) \\
0.1594(0.2201)\end{array}$ & $\begin{array}{r}-0.0359 * *(0.0155) \\
-0.0029(0.0137) \\
-0.0085(0.0819) \\
0.0053 * *(0.0026) \\
-0.0233(0.0516)\end{array}$ & $\begin{array}{r}-0.0384(0.0252) \\
-0.0079(0.0219) \\
0.0917(0.1098) \\
0.0125^{* *}(0.0050) \\
0.2277^{* *}(0.0881)\end{array}$ \\
\hline $\begin{array}{l}\text { External environment } \\
\text { Seriousness of Soil and Water Loss } \\
\text { Cons } \\
\ln \sigma_{u a} \\
\sigma_{u a} \\
\ln \sigma_{u n} \\
\sigma_{u n} \\
\text { LR } \\
\text { Log-likelihood }\end{array}$ & $\begin{array}{c}0.1245 * *(0.0483) \\
0.3951(0.4915) \\
- \\
- \\
- \\
- \\
22.27 \text { *** } \\
-501.89655\end{array}$ & $\begin{aligned}-0.0179 *(0.0118) \\
6.7105^{* * *}(0.1848) \\
-1.1003^{* * *}(0.0929) \\
1.1156 * * *(0.2549) \\
- \\
- \\
- \\
-\end{aligned}$ & $\begin{aligned} & 0.00004(0.0200) \\
& 6.1603 * * *(0.3085) \\
&- \\
&- \\
&-1.1073^{* * * *}(0.0416) \\
&-0.9689 * * *(0.1740) \\
&- \\
&-\end{aligned}$ \\
\hline
\end{tabular}

Notes: $* * * * * * *$ respectively, indicate that the independent variables are significant at the confidence level of $1 \%, 5 \%$ and $10 \%$. The figures in brackets are standard errors
Effects of farmers' adoption behavior

609 
IJCCSM

12,5

610

adapt to climate change. The cultivated land area has a significant positive impact on farmers' adoption of soil and water conservation measures at the $1 \%$ statistical level. The larger the cultivated area is, it means that the main income source of farmers maybe agriculture, which has a strong dependence on farmland. Therefore, more attention is paid to agricultural management. Soil and water loss has a greater impact on farmers with large farmland area, so it is easy to adopt soil and water conservation measures for them. Soil and water loss has a positive and significant impact on farmers' adoption of soil and water conservation measures, at the $5 \%$ statistical level. This indicates that the more serious soil erosion is perceived by farmers, the more they will adopt soil and water conservation measures to cope with the impact and loss caused by soil and water loss. Instrument variable IV government subsidies have a positive and significant impact on farmers' adoption of soil and water conservation measures, at the $1 \%$ statistical level. This indicates that the higher the degree of government subsidies, the more farmers will adopt soil and water conservation measures and government subsidies will help farmers to adopt soil and water conservation measures when other factors remain unchanged. For engineering adaptation measures, farmers may need to invest a lot of money. Government subsidies can help farmers share part of the cost of adopting adaptation measures and promote farmers to adopt them. Biological adaptation measures mainly include afforestation, grass planting, etc. The state implements the project of returning farmland to forestry and grassland, compensates for farmers has promoted the adoption of adaptation measures. Because of the externalities of soil and water conservation measures, government subsidies have a significant incentive effect on farmers to adopt soil and water conservation measures.

\subsection{Analysis of regression result of agricultural output equation}

Soil and water loss has a significant negative impact on the agricultural output of peasant households adopting soil and water conservation measures. Under the premise of keeping other factors unchanged, soil erosion has a significant negative impact on agricultural output, at the $1 \%$ statistical level. Indicating that the more serious soil erosion is, the lower the yield of maize is. Input factors have significant positive effects on the agricultural output of both the adopt farmers and not adopt farmers. The estimation of traditional factor input variables has a significant effect and accords with economic intuition and expectations. The cultivated land area has a significant positive impact on the agricultural output of both the adopt farmers and not adopt farmers. The larger the cultivated land area is, the higher the enthusiasm of farmers in agricultural production, the more conducive to the increase of the output. Joining cooperatives has a significant positive impact on the agricultural output of non-adopted farmers, which indicates that joining cooperatives can increase the agricultural output of farmers, mainly because the technical personnel of cooperative organizations can provide training for farmers in agricultural production technology, help farmers effectively manage farmland and then increase agricultural output. The age of the head of the household has a negative impact on the agricultural output of the adoptive households, which indicates that with the increase of the age of the head of household, the output level of the farmers has decreased. This is mainly because the older the head of the household is, the more conservative the ideology is, which inhibits the improvement of its production efficiency, which is not conducive to the increase of the output.

\subsection{Analysis of treatment effect}

In this paper, equations (8) and (9) are used to calculate the treatment effect of farmers' adoption of soil and water conservation measures on agricultural output. The results are shown in Table 4. Among them, (a) and (b), respectively, represent the expected agricultural output results that farmers actually adopt and actually do not adopt, corresponding to the above equations (4) and 
(5), (c) and (d), respectively, represent the counterfactual hypothesis results, corresponding to equations (6) and (7). The last column in Table 4 shows the average treatment effect of farmers' adoption of soil and water conservation measures on agricultural output. The average treatment effect is significant at the level of $1 \%$. From the perspective of average expected agricultural output, under the counterfactual assumption, when farmers adopt adaptation measures do not adopt it, the average agricultural output per ha will decrease by $0.1433(2.01 \%)$. When farmers do not adopt adaptation measures adopt. Agricultural output per ha will increase by 0.9068 $(12.12 \%)$. This shows that the adoption of soil and water conservation measures by farmers can increase agricultural output.

\subsection{Robustness test}

This paper further tests the robustness of the above results. The bivariate logistic regression model was used to estimate farmers' adoption behavior of soil and water conservation measures. The parameters of the farmer's agricultural output model are estimated by the least-squares method (OLS). The results of the model are shown in Table 5. The regression results of key variables are consistent with the previous conclusions, that is, the adoption of soil and water conservation measures can help increase agricultural output.

Continue to use PSM for robustness tests. Using Stata 14.0 software to estimate the propensity score of the logit model, the dependent variable is "whether farmers adopt soil and water conservation measures" and the independent variable is farmers' capital endowment, government subsidies and external environment. The estimated results are

\begin{tabular}{lccccc}
\hline $\begin{array}{l}\text { Average expected agricultural output }(\mathrm{kg} / \mathrm{ha}) \\
\text { logarithm }\end{array}$ & $\begin{array}{c}\text { Adopting } \\
\text { adaptation } \\
\text { measures }\end{array}$ & $\begin{array}{c}\text { Not adopting } \\
\text { adaptation } \\
\text { measures }\end{array}$ & ATT & ATU \\
\hline Adopting farmers & (a) 7.1103 & (c) 6.9669 & $0.1433^{* * * *}$ & - \\
Not adopting farmers & (d) 7.4801 & (b) 6.5732 & & $0.9068^{* * * *}$
\end{tabular}

Note: ***indicates significant at 1\% level; ATT, ATU indicate the average treatment effect corresponding to the adoption of farmers and the non-adoption of farmers, respectively

Effects of farmers' adoption behavior

611
Table 4.

Analysis of treatment effect

\begin{tabular}{lll}
\hline Variable & Adoption behavior model & Agricultural output model \\
\hline $\begin{array}{l}\text { Soil erosion } \\
\text { Adoption of Soil and Water Conservation } \\
\text { Technology }\end{array}$ & $0.199 * * *(0.068)$ & $-0.013^{* *}(0.007)$ \\
Other variables & & $0.232^{* *}(0.099)$ \\
& Controlled & \\
& Pseudo $R^{2}=0.2116$ & Controlled \\
& Log-likelihood $=$ & F-values $=7.58$ \\
& -595.39879 & Adjust $\mathrm{R}^{2}=0.2369$ \\
& LR $\operatorname{chi}^{2}(11)=319.53^{* * *}$ & Prob $>\mathrm{F}=0.0000$
\end{tabular}

Notes: ***, **, * respectively, indicate that the independent variables are significant at the confidence level of $1 \%, 5 \%$ and $10 \%$. The figures in brackets are standard errors

Table 5. Robustness test 
IJCCSM

12,5

\section{2}

Table 6.

Estimated results of logit model with propensity score shown in Table 6. The regression results of key variables are consistent with the previous conclusions, which shows that the results are robust.

In this paper, Stata 14.0 statistical software was used to evaluate the effect of soil and water conservation measures adopted by peasant households through the PSM nuclear matching process. The specific statistical results are shown in Table 7. Empirical results showed that the average ATT of treatment effect between the treatment group and the control group was 0.4852 , which indicated that the agricultural output of farmers who adopt soil and water conservation measures was $7.53 \%$ higher than that of farmers who did not adopt adaptation measures. That is to say, the average output of maize per ha could be increased to some extent by adopting soil and water conservation measures.

\section{Conclusion and enlightenment}

\subsection{Conclusion}

This paper constructed a theoretical model of the impact of farmers' adoption of soil and water conservation measures on agricultural output. Based on the field survey data of 808 corn growers in three provinces (regions) in the Loess Plateau, using the endogenous switching regression model analyzed the effect of farmers' adoption of soil and water conservation measures on agricultural output. The following conclusions are drawn:

- Soil and water loss has a significant negative impact on maize yield, and soil erosion has a significant positive impact on farmers' adoption of soil and water conservation measures.

\begin{tabular}{|c|c|c|}
\hline Variable & Coefficient & Standard error \\
\hline Age & $-0.4453 * * *$ & 0.1082 \\
\hline Education & -0.1254 & 0.0997 \\
\hline Gender & 0.2171 & 0.5303 \\
\hline Cultivated land area & $0.1749 * * *$ & 0.0194 \\
\hline Agricultural machinery & 0.2043 & 0.1725 \\
\hline Soil erosion & $0.1881 * *$ & 0.0882 \\
\hline Mutual trust & $0.1942 * *$ & 0.0928 \\
\hline Government subsidies & $0.4623 *$ & 0.2549 \\
\hline Cons & 0.0965 & 0.8686 \\
\hline Log-likelihood & \multicolumn{2}{|c|}{-364.97403} \\
\hline LR $\operatorname{chi}^{2}(8)$ & \multicolumn{2}{|c|}{240.75} \\
\hline Pseudo $\mathrm{R}^{2}$ & \multicolumn{2}{|c|}{0.2480} \\
\hline Prob $>\mathrm{chi}^{2}$ & \multicolumn{2}{|c|}{0.0000} \\
\hline
\end{tabular}

Note: ***, **, * respectively, indicate that the independent variables are significant at the confidence level of $1 \%, 5 \%$ and $10 \%$

\section{Table 7.}

Estimated results of average treatment effects of soil and water conservation measures

\begin{tabular}{llrc}
\hline Adoption of soil and water conservation technology & Coefficient & \multicolumn{1}{c}{ Z } & Standard error \\
\hline Average treatment effect in control group (ATT) & $0.4852^{* * * *}$ & 6.93 & 0.07 \\
Average treatment effect of non-participants (ATU) & $0.4284^{* * *}$ & 10.35 & 0.04 \\
Random average processing effect (ATE) & $0.4683^{* * *}$ & 9.07 & 0.05
\end{tabular}

Notes: The standard errors here are calculated by the bootstrap command in Stata 14.1; ATU represents the average treatment effect of non-participants; ATE represents the expected treatment effect of randomly extracting an individual from the population 
- Farmers adopt soil and water conservation measures to cope with changes in soil erosion, which can increase agricultural output. Based on the counterfactual hypothesis, if farmers who adopt soil and water conservation measures do not adopt corresponding soil and water conservation measures, their per ha output will decrease and if farmers who do not adopt soil and water conservation measures adopt corresponding soil and water conservation measures, they are per ha output will increase.

- Government subsidies and cultivated land areas have significant promoting effects on farmers' adoption of soil and water conservation measures.

\subsection{Recommendations}

Based on the above research results, this paper draws the following policy implications:

- Soil and water loss significantly affects the adoption of soil and water conservation measures and reduces agricultural output. The relevant government departments should provide farmers with more information and knowledge on soil and water loss, deepen farmers' awareness of soil and water loss and promote farmers to adopt adaptation measures.

- Strengthen support for farmers to adopt soil and water conservation measures. At present, the proportion of water and soil conservation adaptation measures adopted by peasant households is relatively low. According to the survey experience, it is mainly limited by the factors of high technology cost. Therefore, it is necessary to give adequate consideration to the cost and benefit of water and soil conservation measures. It is necessary to provide appropriate economic support to reduce the cost of water and soil conservation measures adopted by peasant households as far as possible. Then, give full play to the benefits of technology, encourage farmers to adopt soil and water conservation measures and then alleviating the negative impact of soil erosion on agricultural production.

- When formulating policies, the government should consider the impact of farmers' and family endowment characteristics on the adoption of water and soil conservation measures, such as promoting the land transfer of farmers and better encouraging farmers to adopt soil and water conservation measures.

\section{References}

Akpalu, W. and Normanyo, A. (2014), "Illegal fishing and catch potentials among small scale fishers: application of endogenous switching regression model", Environment and Development Economics, Vol. 19 No. 2, pp. 156-172.

Arslan, A., Mc Carthy, N., Lipper, L., Asfaw, S. and Cattaneo, A. (2014), "Adoption and intensity of adoption of conservation farming practices in Zambia", Agriculture, Ecosystems and Environment, Vol. 187, pp. 72-86.

Asfaw, S., Di Battista, F. and Lipper, L. (2016), "Agricultural technology adoption under climate change in the Sahel: micro-evidence from Niger”, Journal of African Economies, Vol. 25 No. 5, pp. 637-669.

Cai, R. and Cai, S. (2012), "The adoption of conservation agricultural and the impact on crop yields based on rice farms in Anhui provinc", Resources Science, Vol. 34 No. 9, pp. 1705-1711.

Cai, R., Wang, Z., Qian, L. and Du, Z. (2019), "Do cooperatives promote family farms to choose environmental-friendly production practices? An empirical analysis of fertilizers and pesticides reduction", China Rural Survey, Vol. 1, pp. 51-65. 
IJCCSM 12,5

614
Chen, W. and Xie, X. (2013), "Study on the mechanism of the impact of climate disasters on food security”, Issues in Agricultural Economy, Vol. 01, pp. 12-19.

Chen, H., Wang, J. and Huang, J. (2014), "Policy support, social capital, and farmers' adaptation to drought in China", Global Environmental Change, Vol. 24 No. 1, pp. 193-202.

Deressa, T.T., Hassan, R.M., Ringler, C., Alemu, T. and Yesuf, M. (2009), "Determinants of farmers' choice of adaptation methods to climate change in the nile basin of Ethiopia", Global Environmental Change, Vol. 19 No. 2, pp. 248-255.

Di Falco, S. and Chavas, J.P. (2009), "On crop biodiversity, risk exposure, and food security in the highlands of Ethiopia", American Journal of Agricultural Economics, , Vol. 91 No. 3, pp. 599-611.

Falco, D., S., Veronesi, M. and Yesuf, M. (2011), "Does adaptation provide food security? A micro perspective from Ethiopia”, American Journal of Agricultural Economics, Vol. 93 No. 3, pp. 829-946.

Feng, X., Liu, M., Huo, X. and Chen, Z. (2017), "The effects of farmers' adaptation to climate change on agricultural production: a case study on apple farmers in shaanxi", Chinese Rural Economy, Vol. 3, pp. 31-45.

Finger, R., Hediger, W. and Schmid, S. (2011), "Irrigation as adaptation strategy to climate change - a biophysical and economic appraisal for Swiss maize production”, Climatic Change, Vol. 105 No. 3, pp. 509-528.

Guo, X., Zhou, L., Chen, Y., Zhao, M. and Wang, R. , (2017), "Perception and adaption of ecological environment change for farmers in the typical desertification area: a case of hangjin banner in the Inner Mongolia autonomous region", Journal of Arid Land Resources and Environment, Vol. 31 No. 03, pp. 64-69.

Habiba, U., Shaw, R. and Takeuchi, Y. (2012), "Farmer's perception and adaptation practices to cope with drought: perspectives from northwestern Bangladesh", International Journal of Disaster Risk Reduction, Vol. 1, pp. 72-84.

Huang, J. and Wang, J. (2014), "Farmers' adaptation to extreme weather events through farm management and its impacts on the mean and risk of rice yield in China", American Journal of Agricultural Economics, Vol. 97 No. 2, pp. 602-617.

Huang, J.K., Wang, J.X. and Wang, Y.J. (2015), "Farmers' adaptation to extreme weather events through farm management and its impacts on the mean and risk of rice yield in China", American Journal of Agricultural Economics, Vol. 97 No. 2, pp. 602-617.

Jara-Rojas, R., Bravo-Ureta, B.E. and Díaz, J. (2012), “Adoption of water conservation practices: a socioeconomic analysis of small-scale farmers in Central Chile", Agricultural Systems, Vol. 110, pp. 54-62.

Ji, A. (2017), "Mechanism analysis and empirical model of investment behavior of soil and water conservation in donggang city farmer", Heilongjiang Hydraulic Science and Technology, Vol. 45 No. 8, pp. 224-226.

Kabir, M.H. and Rainis, R. (2015), "adoption and intensity of Integrated Pest Management (IPM) vegetable farming in Bangladesh: an approach to sustainable agricultural development", Environment, Development and Sustain, Vol. 17 No. 6, pp. 1413-1429.

Khisa, P., Gachene, C.K., Karanja, N. and Mureithi, J. (2007), "The effect of post harvest crop cover on soil erosion in a maize-legume based cropping system in gatanga, Kenya", Journal of Agriculture in the Tropics and Subtropics, Vol. 103, pp. 17-28.

Li, W., Xue, C., Yao, S. and , Zhu, R. (2017), "Conservation tillage, cropping systems and land productivity for households on the Loess Plateau", Resources Science, Vol. 39 No. 7, pp. 1259-1271.

Li, Y. (2017), "Behavior mechanism analysis of farmers' soil and water conservation in hilly areas of North China: a case study of Liaoning South ticket area", Technical Supervision in Water Resources, Vol. 25 No. 5, pp. 103-105.

Luo, X., Feng, S., Shi, X. and Qu, F. (2013), "Farm households'Adoption behavior of environment friendly technology and the evaluation of their environmental and economic effects in Taihu 
basin - taking formula fertilization by soil testing technology as an example", Journal of Natural Resources, Vol. 28 No. 11, pp. 1891-1902.

Maddison, D. (2006), "The perception of and adaptation to climate change in africa", World Bank working paper, No.4308.

Mainuddin, M., Kirby, M. and Hoanh, C.T. (2011), "Adaptation to climate change for food security in the lower mekong basin", Food Security, Vol. 3 No. 4, pp. 433-450.

Truelove, H.B., Carrico, A.R. and Thabrew, L. (2015), "A socio-psychological model for analyzing climate change adaptation: a case study of sri lankan paddy farmers", Global Environmental Change, Vol. 31, pp. 85-97.

Wang, Y. (2013), "Thoughts on soil and water loss in the Loess Plateau", Shaanxi Water Resources, Vol. 06, pp. 53-54.

Xinhua News Agency (2010), available at: www.gov.cn/jrzg/2010-10/29/content_1733482.htm

Yang, Y., Wang, J. and Hang, J. (2016), "Extreme drought events, farmland management adaptive behavior and production risk: an empirical study based on farmers in North China plain", Journal of Agro-Technical Economics, Vol. 09, pp. 4-17.

Yang, Y., Wang, J. and Hang, J. (2016), "The adaptive irrigation behavior of farmers and impacts on yield during extreme drought events in the North China plain", Resources Science, Vol. 38 No. 5, pp. 899-907.

Yang, Y., Wang, J. and Hou, L., (2018), "Extreme drought events and rural poverty: differences on farmers'adaptive behavior and production impacts among different income groups in North China plain”, China Population, Resources and Environment, , Vol. 28 No No. 1, pp. 124-133.

Yesuf, M., Falco, D.S., Deressa, T., Ringler, C. and Kohlin, G. (2008), “The impact of climate change and adaptation on food production in low-income countries: Evidence from the nile basin, Ethiopia", IFPRI Discussion Paper 828.

Ying, E. (2018), "Harm of soil and water loss and measures of soil and water conservation", Heilongjiang Hydraulic Science and Technology, Vol. 46 No. 7, pp. 275-277.

Zhai, W. and Hang, X. (2005), "Analysis on the mechanism of farm household behavior of water and soil conservation", Research of Soil and Water Conservation, Vol. 06, pp. 112-116.

Zhao, X. (2014), "A review of farmers' perception and adaptation to climate change”, Ying Yong Sheng Tai Xue Bao = the Journal of Applied Ecology, Vol. 25 No. 8, pp. 2440-2448.

Zhao, L. and Cai, S. (2013), "Analysis of pesticide cost saving and grain yield increasing effect of IPM technology adopted by late rice planting farmers", Chinese Rural Economy, Vol. 05, pp. 78-87.

\section{Corresponding author}

Qian Lu can be contacted at: luqian@nwafu.edu.cn

For instructions on how to order reprints of this article, please visit our website: 